\title{
Ouabain Effects on Intracellular Potassium Activity and Contractile Force in Cat Papillary Muscle
}

\author{
David J. Browning, Thomas Guarnieri, and Harold C. Strauss, Departments of \\ Medicine and Pharmacology, Duke University Medical Center, \\ Durham, North Carolina 27710
}

A B S T RA C T The relationship between the positive inotropic and toxic effects of cardiac glycosides and their effects on intracellular ionic composition is incompletely defined. We measured intracellular potassium activity $\left(\alpha_{\mathrm{k}}^{\mathrm{i}}\right)$, extracellular potassium activity $\left(\alpha_{\mathrm{k}}^{\mathrm{e}}\right)$, resting potential, action potential duration, and contractile force at $32^{\circ} \mathrm{C}$ in paired papillary muscles from feline right ventricles exposed to ouabain. Muscles used for electrophysiological measurements were quiescent except for isolated stimulation to confirm impalement and record action potential duration. Muscles used for contractile force measurements were quiescent except for 4-min periods when force was measured at a cycle length of $1,400 \mathrm{~ms}$. Muscle length was adjusted to achieve $50 \%$ of maximal tension at this cycle length before each experiment. In four experiments, $\alpha_{\mathrm{K}}^{\mathrm{l}}$ and contractile force were measured in the same muscle. $\alpha_{\mathrm{k}}^{\mathrm{k}}$ was measured with single and double-barrel K-sensitive electrodes. At $10 \mathrm{nM}$ ouabain, action potential duration is prolonged. Among the concentrations tested, the threshold for a clear positive inotropic effect is $0.1 \mu \mathrm{M}$ ouabain. The threshold for decrease in $\alpha_{\mathrm{k}}^{\mathrm{i}}$, increase in $\alpha_{\mathrm{k}}^{\mathrm{e}}$, and decrease in membrane potential is $1 \mu \mathrm{M}$, at which concentration toxic signs develop, including arrhythmias, aftercontractions, and alteration in the staircase response of contractile force to repetitive stimulation. Ouabain need not change $\alpha_{\mathrm{K}}^{\mathrm{i}}$ to effect positive inotropy in ventricular muscle, a relationship different from that reported between $[\mathrm{K}]_{\mathrm{i}}$ (intracellular potassium concentration) and positive inotropy. Higher ouabain concentrations, which others have shown to clearly inhibit active $\mathrm{Na}$ and $\mathrm{K}$ transport, are shown to upset

Dr. Browning's work was done as partial fulfillment of the requirements for the $\mathrm{Ph}$.D. thesis from the Graduate School of Arts and Sciences, Duke University. $\mathrm{He}$ is an Insurance Medical Scientist Scholarship Fund Awardee. Dr. Strauss is a Research Career Development Awardee (1-K04-HL-HL00268) of the National Heart, Lung, and Blood Institute.

Received for publication 6 October 1980 and in revised form 17 June 1981. intracellular potassium activity homeostasis and to consistently produce toxicity.

\section{INTRODUCTION}

Cardiac glycosides have no direct effect on the contractile proteins of the heart $(1,2)$, but are known to affect the sarcolemmal sodium-potassium pump. For this reason, many studies have examined the correlation of changes in intracellular ionic concentration or activity with positive inotropic and toxic effects. In studies on guinea pig atrium, Noack et al. (3) found an increase in cellular potassium at the time of positive inotropic effect, whereas Busse et al. (4) found no change in cellular potassium. Both groups observed the association of decreased cellular potassium and glycoside toxicity. In studies on sheep Purkinje fibers, Ellis (5) found no change in intracellular sodium activity at a glycoside concentration known to be positively inotropic in this tissue (6). Using the same tissue but a different glycoside, Lee et al. (7) never observed increased contractile force without a concomitant increase in sodium activity. Thus, in neither guinea pig atrium nor sheep Purkinje fibers does a consensus exist concerning the correlation of cytoplasmic ionic changes and the positive inotropic effects of glycosides.

The primary target tissue in the clinical use of cardiac glycosides is the ventricular myocardium. Correlations of cytoplasmic ionic changes and inotropic effects have not been well defined in this tissue either. Whereas both Müller (8) and Langer and Serena (9) found that cellular potassium was always decreased at the onset of positive inotropic effect, Ruiz-Ceretti et al. (10) found a slight increase. No study exists in which intracellular potassium activity $\left(\alpha_{\mathrm{k}}^{\mathrm{j}}\right)^{1}$ and contractile

\footnotetext{
${ }^{1}$ Abbreviations used in this paper: AC's, aftercontractions; APD, action potential duration; $\alpha_{\mathrm{k}}^{\mathrm{i}}$, intracellular potassium activity; $\alpha_{\mathrm{K}}^{\mathrm{e}}$, extracellular potassium activity; $\gamma_{\mathrm{K}}$, activity coefficient; $i_{K_{2}}$, time dependent outward potassium current,
} 
force are measured at the same time in paired ventricular muscles. In this study we report the results of experiments of this type. In addition to their general interest, such measurements of $\alpha_{\mathrm{K}}^{\mathrm{i}}$ bear specifically on the controversy regarding Na-K pump stimulation or inhibition and the positive inotropic effect of glycosides. When coupled with measurements of extracellular space potassium activity $\left(\alpha_{\mathrm{k}}^{\mathrm{e}}\right)$, they also address the novel mechanism of positive inotropic effect advanced by Greenspan and Morad (11) involving a potassium-calcium exchange.

We used a wide range of glycoside concentrations in this study. The lowest approximate those of free drug in the plasma of patients, and have been reported to stimulate (12) or inhibit (13) Na-K pumping. The highest are frankly toxic in in vivo and unequivocally inhibit Na-, K-pump function in vitro. Thus, our temporal correlation of $\alpha_{\mathrm{K}}^{\mathrm{i}}$ with contractile force should encompass the possibility that glycoside actions and mechanisms are multiple and concentrationdependent. In several experiments we go further and examine the temporal correlations of effects on $\alpha_{\kappa}^{\mathrm{e}}$ and percentage of cell volume with the positive inotropic effects of glycosides.

\section{METHODS}

Cats weighing 1.5-3.0 kg were anesthetized with sodium pentobarbital, $30 \mathrm{mg} / \mathrm{kg}$ i.p. The hearts were rapidly removed and immersed in Tyrode's solution of the following composition in $\mathrm{mM}$ : $\mathrm{NaCl}, 135.4 ; \mathrm{KCl}, 5.4 ; \mathrm{NaH}_{2} \mathrm{PO}_{4}, 1.8$; $\mathrm{CaCl}_{2}, 2.7 ; \mathrm{MgCl}_{2}, 0.5 ; \mathrm{NaHCO}_{3}, 18$; and dextrose, 5.5. Solutions were bubbled with $95 \% \mathrm{O}_{2}-5 \% \mathrm{CO}_{2}$. Bath temperature was $32 \pm 1^{\circ} \mathrm{C}$ and bath flow rate $15 \mathrm{ml} / \mathrm{min}$.

The muscle used for measurement of contractile force was tied at both ends with $6-0$ vicryl (Ethicon, Inc., Somerville, N. J.) suture. One end was tied to a Grass FTO3C (Grass Instrument Co., Quincy, Mass.) force transducer and the other end to the arm of a micromanipulator. By adjusting the micromanipulator vernier, various degrees of stretch were applied to the muscle and a length-tension curve generated at a stimulation cycle length of $1,400 \mathrm{~ms}$. On the basis of this curve, the muscle was set at the length corresponding to $50 \% \mathrm{~L}_{\max }$. The mean control contractile force of 21 muscles was $548 \pm 60 \mathrm{mg}$ (SEM).

Intracellular and extracellular potassium activity measure-

thought to be the pacemaker current in Purkinje fibers; $\mathrm{K}$, electrode selectivity coefficient; $[\mathrm{K}]_{\mathrm{i}}$, intracellular potassium concentration; $\mathrm{L}_{\max }$, length to which muscle had to be stretched in order to develop $50 \%$ of maximal tension at a cycle length of $1,400 \mathrm{~ms}$. S, electrode slope; $\mathrm{T}$, contractile force measured at different times; $T_{c}$, control contractile force measured at time $0 . V_{1}$, voltage drop across partition with the muscle absent from the hole; $V_{2}$, voltage drop across partition with the muscle present in the hole; $V_{K}^{x}, V_{K}^{e}$ (potassium electrode reading in extracellular space) or $V_{K}^{1}$ (potassium electrode reading in extracellular space); $V_{K}^{0}$, potassium electrode reading in superfusate; $V_{K}=V_{K}^{x}-V_{k}^{o} ; V_{m}^{x}, V_{m}^{e}$ (reference electrode reading in extracellular space) or $V_{m}^{i}$ (reference electrode reading in intracellular space). $V_{m}^{o}=$ reference electrode reading in super-fusate; $V_{m}=V_{m}^{x}-V_{m}^{o}$. ments were made with potassium liquid ion exchanger microelectrodes, fabricated as described (14). Single-barrel electrodes were used for most experiments, but, in specific instances, double-barrel electrodes were used as noted in the text. The equation used to calculate $\alpha_{\mathrm{K}}^{\mathrm{l}}$ or $\alpha_{\mathrm{K}}^{\mathrm{e}}$ is as follows:

$\alpha_{\mathrm{K}}^{\mathrm{x}}=\left(\alpha_{\mathrm{K}}^{0}+\mathrm{K} \alpha_{\mathrm{Na}}^{0}\right) \exp \left\{\frac{2.303}{\mathrm{~S}}\left[\left(\mathrm{~V}_{\mathrm{K}}^{\mathrm{x}}-\mathrm{K}_{\mathrm{K}}^{0}\right)-\left(\mathrm{V}_{\mathrm{m}}^{\mathrm{x}}-\mathrm{V}_{\mathrm{m}}^{\mathrm{o}}\right)\right]\right\}-\mathrm{K} \alpha_{\mathrm{Na}}^{\mathrm{x}}$,

where

$\alpha_{\mathrm{K}}^{\mathrm{x}}=\alpha_{\mathrm{K}}^{\mathrm{e}}$ (extracellular potassium activity) or $\boldsymbol{\alpha}_{\mathrm{K}}^{\mathrm{i}}$ (intracellular potassium activity).

$\alpha_{\mathrm{K}}^{0}=$ potassium activity of superfusate.

$\alpha_{\mathrm{Na}}^{0}=$ sodium activity of superfusate.

$\alpha_{\mathrm{Na}}^{\mathrm{x}}=\alpha_{\mathrm{Na}}^{\mathrm{e}}$ (extracellular sodium activity) or $\alpha_{\mathrm{Na}}^{\mathrm{i}}$ (intracellular sodium activity).

$V_{\mathbf{K}}^{x}=V_{\mathbf{K}}^{e}$ (potassium electrode reading in extracellular space) or $V_{K}^{1}$ (potassium electrode reading in intracellular space).

$V_{\mathbf{K}}^{0}=$ potassium electrode reading in superfusate.

$\mathrm{V}_{\mathbf{K}}=\mathrm{V}_{\mathrm{K}}^{\mathrm{x}}-\mathrm{V}_{\mathbf{K}}^{\mathbf{0}}$.

$V_{m}^{x}=V_{m}^{e}$ (reference electrode reading in extracellular space) or $V_{m}^{i}$ (reference electrode reading in intracellular space).

$V_{m}^{o}=$ reference electrode reading in superfusate.

$\mathrm{V}_{\mathrm{m}}=\mathrm{V}_{\mathrm{m}}^{\mathrm{x}}-\mathrm{V}_{\mathrm{m}}^{\mathrm{o}}$.

$\mathrm{K}=$ electrode selectivity coefficient.

$\mathrm{S}=$ electrode slope.

Potassium electrodes had slopes $>55 \mathrm{mV} /$ decade change in potassium activity and selectivity coefficients $<0.03$. Tip resistance ranged from $10^{9}-10^{10} \Omega$. In $\alpha_{\mathrm{k}}^{\mathrm{i}}$ determinations, $K \alpha_{\mathrm{Na}}^{\mathrm{i}}$ was neglected, since $\alpha_{\mathrm{Na}}^{\mathrm{i}}<10 \mathrm{mM}(15)$ and $\mathrm{K}<0.03$. Against a background potassium concentration of $150 \mathrm{mM}$, the minimum detectable change in potassium concentration with a given $\mathrm{K}$ electrode averaged $1.5 \mathrm{mM}$.

Fig. 1 illustrates how the value for the minimum de-

A

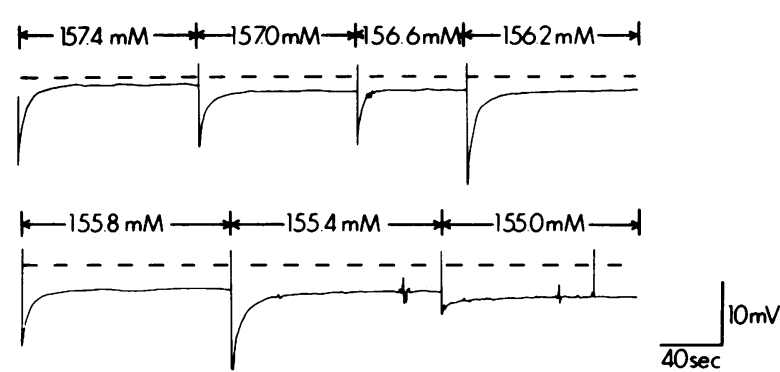

B

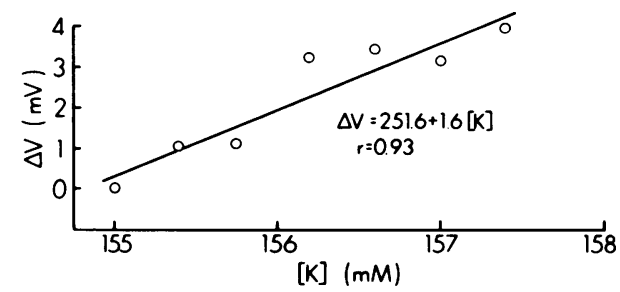

FIGURE 1 Determination of the minimum change in [K] detectable by potassium-sensitive electrode against a background potassium concentration of $150 \mathrm{mM}$. Recordings of electrode response to $0.4 \mathrm{mM}$ changes in [K]. Dotted line provides a reference potential level (A). Plot of change in electrode reading vs. [K]. The least squares' best fit line is defined by the equation shown (B). Further explanation in text. 
tectable change was derived. A series of solutions of pure $\mathrm{KCl}$ were made up in which $[\mathrm{KCl}]$ was increased in steps of $0.4 \mathrm{mM}$ with a constant background concentration of $150 \mathrm{mM}$. Strip chart recordings and digital voltmeter readings were taken as the electrode was dipped in successive solutions. For each electrode the readings were plotted vs. [ $\mathrm{KCl}]$ and a least squares best fit line derived. In the four electrodes tested, the correlation coefficient, $r$, for the fit exceeded 0.93 . From the best fit equation, predicted electrode readings were obtained at each concentration tested and this value compared with that actually measured. In 39 solution changes the maximal deviation was $2 \mathrm{mV}$ and the mean deviation $1.1 \mathrm{mV}$. We therefore assumed that any change in electrode reading exceeding $2 \mathrm{mV}$ represented a change in the potassium concentration of the solution sampled and not an electrode sensing error. From the best fit equations the change in $\mathrm{K}$ concentration required to produce a $2 \mathrm{mV}$ change in electrode reading was calculated. The average value was $1.5 \mathrm{mM}$ for the four electrodes tested.

Cell volume measurements were made using the electrophysiological method of Houser and Freeman (16). In this method the muscle is placed in the hole of a partition separating two chambers of a bath. When constant current is passed between bath chambers, the voltage drop across the partition is inversely proportional to the fraction of the hole comprised of extracellular space. By measuring the voltage drop, $V_{1}$, with the muscle absent from the hole, and of $V_{2}$, with the muscle present, the percentage of cell volume is calculated as follows:

$$
\left[1-\frac{V_{1}}{V_{2}}\right] \times 100 \% .
$$

Action potential duration (APD) was measured as the time between the two points at which the action potential crosses the take-off potential.

Experimental protocol. Muscles were allowed to equilibrate for $1 \mathrm{~h}$ before beginning measurements. Three types of protocols were used in an attempt to compensate for particular deficiencies of each protocol when used alone. In 40 experiments, separate muscles were used for measurements of $\alpha_{\mathrm{k}}^{\mathrm{i}}$ or contractile force. In 29 of these experiments both $\alpha_{\mathrm{k}}^{\mathrm{i}}$ and contractile force were measured in muscle pairs taken from the same right ventricle. Both muscles were placed in the same tissue bath for the paired-muscle experiments. In these experiments, control measurements of $\alpha_{\mathrm{K}}^{\mathrm{i}}$ and contractile force were made and then solutions were switched to the ones containing ouabain $1 \mathrm{nM}-10 \mu \mathrm{M}$ (Sigma Chemical Co., St. Louis, Mo.). At $30 \mathrm{~min}$ intervals, until inexcitability or arrhythmias developed, or until $3 \mathrm{~h}$ of drug exposure was reached, repeat measurements of $\alpha_{\mathrm{k}}^{\mathrm{l}}$ and force were made. Contractile force was measured as the amplitude of the transducer recording at the end of $4 \mathrm{~min}$ stimulation at a cycle length of 1,400 ms. Except for these brief periods of measurement, muscles were kept quiescent. The muscles from which $\alpha_{\mathrm{k}}^{1}$ was measured were quiescent except when stimulated to verify electrode impalement. In this protocol, $\alpha_{\mathrm{K}}^{\mathrm{i}}$ and contractile force could be measured at approximately the same time.

In a second set of four experiments, $\alpha_{K}^{1}$ and contractile force were measured in the same muscle. Because it was not possible to maintain electrode impalements for $\alpha_{\mathrm{k}}^{\mathrm{i}}$ measurements during the 4-min stimulation period of the force measurement, $\alpha_{\mathrm{k}}^{\mathrm{i}}$ had to be measured before and after stimulation. Although this method did not truly control for the $4 \mathrm{~min}$ of stimulation, it did provide a way to detect if such intermittent stimulation altered the time course of $\alpha_{\mathrm{k}}^{\mathrm{i}}$ changes. In addition, the possible effects of stretching the muscle to the point of $50 \%$ of maximal steady-state force development were included in this protocol.
The first two protocols involve multiple impalements of different cells at different times during ouabain exposure. The advantage is that measurements are made over time spans of a few seconds so that the drifts in junction potentials at both grounds and in offset potentials across high resistance electrodes are insignificant. However, as has been documented before (Table I, [17]) there is significant variation in intracellular activity measurements from the different cells of a single muscle. Ladle and Walker (17) reported a mean "among impalements" SD of $8.7 \mathrm{mM}$ for $\alpha_{\mathrm{k}}^{\mathrm{k}}$ measurements in sinus venous (four to six pairs of impalements/ muscle, nine muscles). In three muscles for which we obtained four pairs of impalements, we found a comparable figure of $8.7 \mathrm{mM}$ for $\alpha_{\mathrm{K}}^{1}$ measurements. This degree of variation is compounded by the wide variation in $\alpha_{\mathrm{k}}^{\mathrm{l}}$ between muscles (18), so that pooling data from several impalements and muscles is too insensitive a method to detect the small $\alpha_{k}^{1}$ changes one might anticipate during exposure to low concentrations of ouabain.

For this reason we performed a third set of experiments in which $\alpha_{\mathrm{K}}^{\mathrm{l}}$ or $\alpha_{\mathrm{K}}^{\mathrm{e}}$ was measured continuously, in a single cell, throughout the control period and periods of ouabain exposure. As previously mentioned, K-sensitive electrodes used in this setting can detect changes in [K] of $1.5 \mathrm{mM}$ (equal to changes in $\alpha_{\mathrm{K}}$ of $1.1 \mathrm{mM}$ ). Thus, these experiments are sufficiently sensitive to detect changes in $\alpha_{\mathrm{K}}^{1}$ and $\alpha_{\mathrm{K}}^{\mathrm{e}}$ of magnitudes equal to those changes in $\alpha_{\mathrm{Na}}^{\mathrm{i}}$ previously reported for Purkinje fibers during glycoside exposure (19). The compensatory disadvantages of this protocol are twofold: (a) a double barrel K-sensitive electrode must be used, and these cause some cell damage and lowering of $\alpha_{\mathrm{k}}^{\mathrm{k}}$ measurements due to their larger tips; $(b)$ the drifts in reference and offset potentials occurring over the course of several hours require correction based on assumptions regarding drift rate. In our experiments the measured total drift over the course of the experiment was divided by the time to yield a drift rate that was assumed to be constant throughout the experiment.

The use of $\alpha_{K}^{i}$ and $\alpha_{K}^{e}$ as indices of Na-K pump stimulation and inhibition. When there is a significant diffusion barrier between the extracellular space of cardiac preparations and the surrounding bath, $\alpha_{\mathrm{K}}^{\mathrm{e}}$ is a good indicator of transient changes in Na-K pump rate. This was first shown, indirectly, by Cohen et al. (20) by measuring reversal potentials for $\mathbf{i}_{\mathbf{K}_{\mathbf{2}}}$ in sheep Purkinje fibers exposed to ouabain, and later, directly with potassium-sensitive electrodes in rabbit atrium by Kunze (14), and in cat ventricle by Browning and Strauss (21). The relationship of $\alpha_{\mathrm{K}}^{\mathrm{d}}$ to $\mathrm{Na}-\mathrm{K}$ pump rate is not direct, in that other variables must be measured in order to draw a conclusion. For instance, pump rate could increase and yet $\alpha_{\mathrm{K}}^{1}$ not change if cell volume increased or if the net influx of potassium were bound or sequestered in intracellular organelles. In this study we show that ouabain does not change cell volume, but we make no cellular potassium content measurements. Therefore, where the data on $\alpha_{\mathrm{k}}^{\mathrm{e}}$ have direct implications to changes in Na-K pump rate, the data on $\alpha_{k}^{1}$ do not. The proper interpretation of the $\alpha_{k}^{i}$ data requires drawing on the evidence of $\alpha_{\mathrm{k}}^{\mathrm{e}}$ measurements and on other studies in which cellular potassium content was measured (8).

Statistical analysis. Errors are expressed as SEM. Student's $t$ test for paired data is used in tests of significance.

\section{RESULTS}

Correlation of $\alpha_{K}^{i}$ and positive inotropic effects. In Fig. 2 representative records are shown for a pair of muscles exposed to $0.1 \mu \mathrm{M}$ ouabain. Fig. $2 \mathrm{~A}$ shows the control recordings of the reference electrode, $V_{m}$ 
A

CONTROL

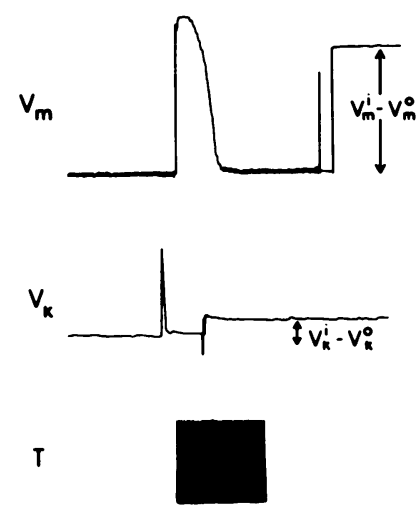

B

$90 \mathrm{~min}$. of $0.1 \mu \mathrm{M}$ OUABAIN

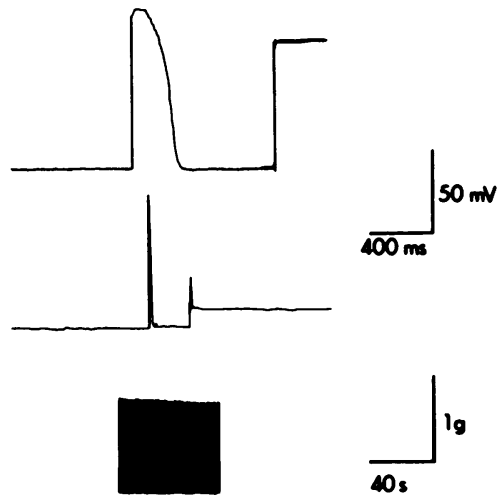

FIgURE 2 Demonstration of development of positive inotropy before change in $\alpha_{\mathrm{K}}^{\mathrm{i}}$ in cat ventricular muscle exposed to ouabain. Control recordings of $V_{m}, V_{K}$, and contractile force (T) (A). Recordings after 90 min exposure to $0.1 \mu \mathrm{M}$ ouabain. The quantities $V_{k}^{1}-V_{k}^{o}$ and $V_{m}^{1}-V_{m}^{o}$ used in the computation of $\alpha_{\mathrm{K}}^{\mathrm{i}}$ are illustrated (B). The tops of the action potentials are missing because of the chart recorder gain setting, chosen in order to have the resting potential measurement occupy as much of the recording surface as possible.

(top), K-sensitive electrode, $\mathrm{V}_{\mathrm{K}}$ (middle), and contractile force, $\mathrm{T}$ (bottom). Fig. 2B shows analogous recordings taken after $90 \mathrm{~min}$ of exposure to drug. Contractile force has increased $13 \%$ at this time, $\alpha_{\mathrm{K}}^{\mathrm{i}}$ has changed from $96 \mathrm{mM}$ to $92 \mathrm{mM}$, which is an insignificant decrease given the error in $\alpha_{\mathrm{K}}^{\mathrm{i}}$ determination.

Pooled measurements of contractile force and $\alpha_{\mathrm{K}}^{\mathrm{i}}$ are shown in Figs. 3 and 4, respectively. Fig. 3 illustrates the development of increased contractile force during ouabain exposure. Contractile force at each time is expressed as a ratio $T / T_{c}$ to the control force measured at time zero. In Fig. 3A, measurements in control muscles, not exposed to ouabain, show that there is no deterioration of force over a 3-h period. In Fig. 3B, a family of curves corresponding to different ouabain concentrations is illustrated; at any given time, contractile force is greater the higher the ouabain concentration. At $1 \mathrm{nM}$ ouabain, no positive inotropic effect is seen. With the stimulation protocol and ouabain concentrations we used, a suggestion of positive inotropic effect is evident at $10 \mathrm{nM}$ and the clearcut threshold is $0.1 \mu \mathrm{M}$.

Fig. 4 illustrates that the threshold concentration for effect on $\alpha_{\mathrm{K}}^{\mathrm{l}}$ is $1 \mu \mathrm{M}$ (D, unfilled squares). Exposure to this concentration for $60 \mathrm{~min}$ produces a significant decrease in $\alpha_{\mathrm{k}}^{\mathrm{i}}(P<0.05)$. No significant change in $\alpha_{\mathrm{k}}^{\mathrm{i}}$ occurred from any duration of exposure to ouabain 0.1 $\mu \mathrm{M}(P>0.05)$.

Potassium activity and contractile force measurements during exposure to $0.1 \mu \mathrm{M}$ ouabain were analyzed to address whether or not positive inotropy can develop in the absence of changes in $\alpha_{\mathrm{K}}^{\mathrm{i}}$. Because the positive inotropic effect is essentially fully
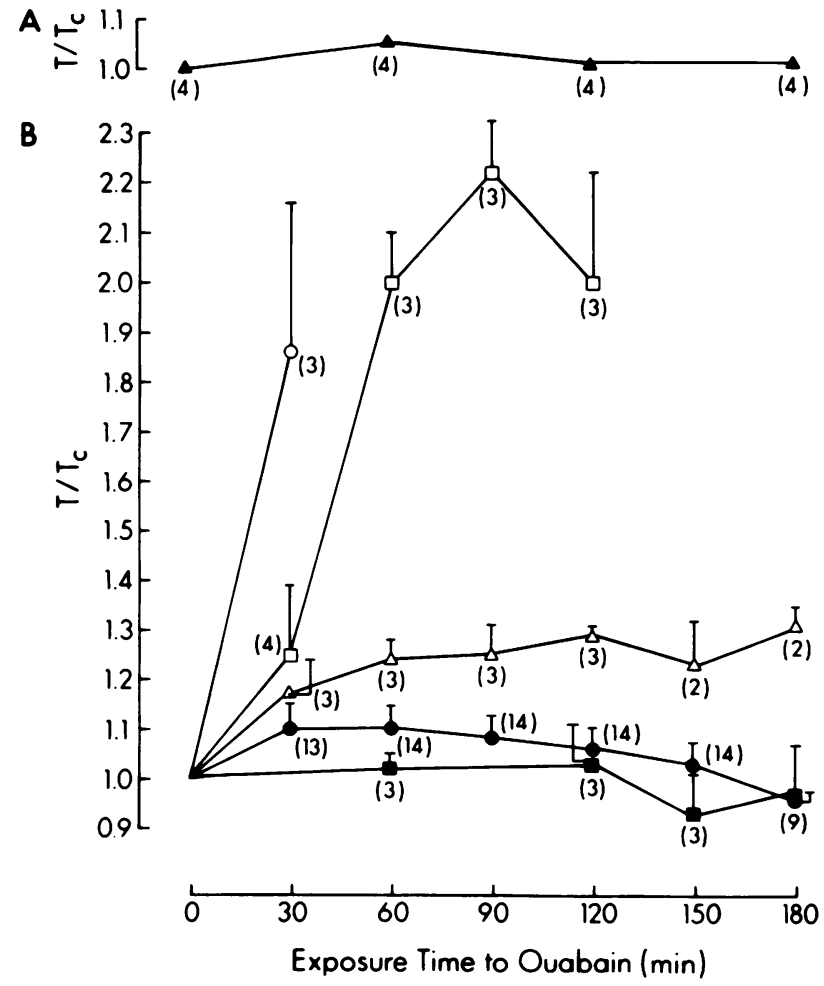

Figure 3 Pooled measurements of contractile force in cat ventricular muscles before and at 30 min intervals after exposure to ouabain. Filled triangles represent control muscles not exposed to ouabain (A). Muscles exposed to different concentrations of ouabain. (B). Open circles represent muscles exposed to $10 \mu \mathrm{M}$ ouabain. Similarly, open squares, open triangles, filled circles, and filled squares represent 1 $\mu \mathrm{M}, 0.1 \mu \mathrm{M}, 10 \mathrm{nM}$, and $1 \mathrm{nM}$ ouabain, respectively (B). 

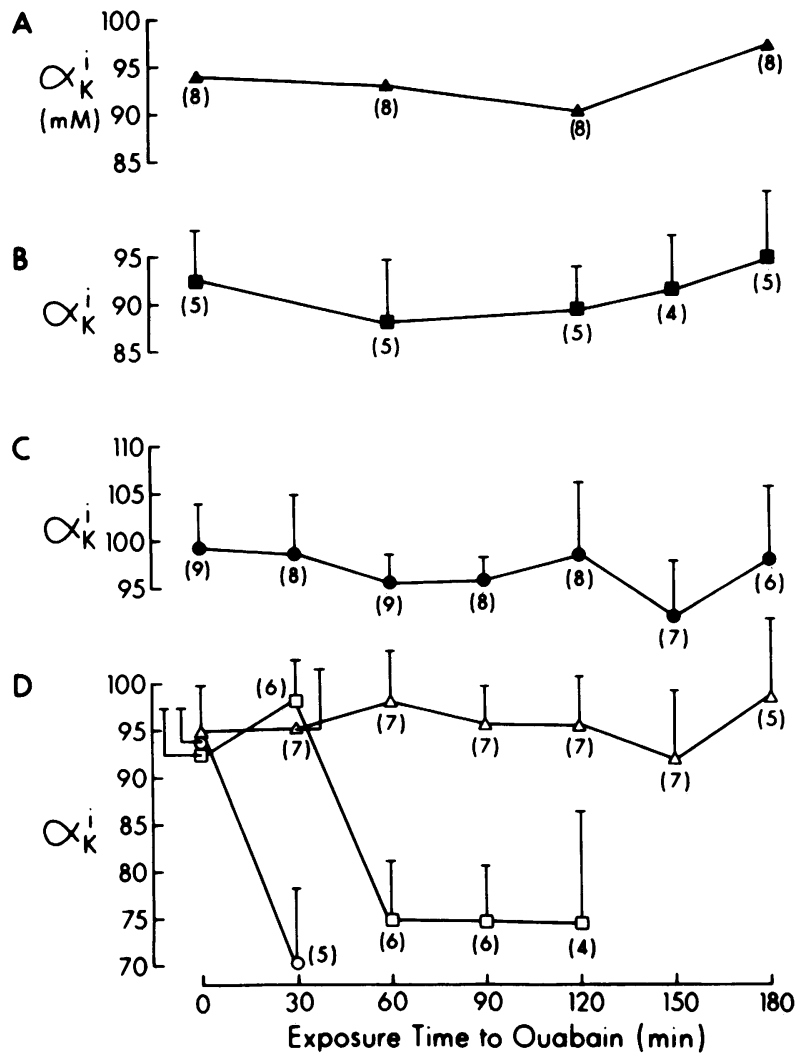

Figure 4 Pooled measurements of $\alpha_{\mathrm{k}}^{\mathrm{j}}$ before and at time intervals after exposing cat ventricular muscles to ouabain. A, B, and $\mathrm{C}$ correspond to control muscle, muscles exposed to $1 \mathrm{nM}$, and muscles exposed to $10 \mathrm{nM}$ ouabain, respectively. In $\mathrm{D}$, open triangles, open squares, and open circles represent muscles exposed to $0.1,1.0$ and $10 \mu \mathrm{M}$ ouabain, respectively.

developed after 60 min exposure (Fig. 3), measurements of contractile force and $\alpha_{\mathrm{K}}^{\mathrm{i}}$ at this time were compared to control values. Whereas contractile force had increased significantly $(P<0.01), \alpha_{\mathrm{K}}^{\mathrm{k}}$ at the two times did not differ significantly.

The measurements shown in Fig. 4 were obtained by taking means of multiple impalement of different cells by separate reference and K-sensitive electrodes. Because cell-to-cell inhomogeneities can exist within a preparation (21), an important complementary experiment is to maintain an impalement of a single cell with a double-barrel electrode before and during a treatment change. Such an experiment is illustrated in Fig. 5 together with the contractile force measurements from the paired muscle. The muscle had already been exposed to $10 \mathrm{nM}$ and $0.1 \mu \mathrm{M}$ ouabain previous to the recordings illustrated, without any change in $\alpha_{\mathbf{k}}^{1}$. Over the period of time shown in the figure, the superfusate was switched from one containing $0.1 \mu \mathrm{M}$ to one containing $1 \mu \mathrm{M}$ ouabain. During the first $30 \mathrm{~min}$ of exposure to the higher concen- tration, the contractile force has clearly increased, but neither the reference barrel recording $\left(V_{m}\right)$, nor the potassium barrel recording $\left(\mathrm{V}_{\mathrm{K}}\right)$ has changed, indicating no change in $\alpha_{\mathrm{k}}^{\mathrm{i}}$. This reflects the result shown in the pooled measurements of $\alpha_{\mathrm{K}}^{\mathrm{L}}$ in Fig. 4. The first decrease in $\alpha_{\mathrm{K}}^{\mathrm{1}}$ in muscles exposed to $1 \mu \mathrm{M}$ ouabain is at $60 \mathrm{~min}$.

The experiments summarized in Figs. 3-5 involve measurements of $\alpha_{\mathrm{K}}^{\mathrm{i}}$ and contractile force in separate muscles. Whereas the muscles from which contractile force was measured were stimulated for $4 \mathrm{~min}$, those from which $\alpha_{\mathrm{k}}^{\mathrm{i}}$ was measured were not. Thus the validity of the temporal correlations of the two sets of measurements is open to question. To address this issue, we performed four experiments in which we measured $\alpha_{\mathrm{K}}^{\mathrm{i}}$ in the same muscle in which contractile force was measured. The $\alpha_{\mathrm{K}}^{1}$ measurements were made quickly in the quiescent muscles before and after contractility measurements and the results were averaged. In several cases we were unable to obtain good pairs of impalements for the $10 \mathrm{~min}$ preceding or following the $4 \mathrm{~min}$ of stimulation. In these cases only the before stimulation or after stimulation results were used to compute $\alpha_{\mathrm{k}}^{1}$. Attention was focused on $0.1 \mu \mathrm{M}$ ouabain and exposure times of 30 and $60 \mathrm{~min}$, because these are the concentration and times at which clearcut positive inotropic effects are seen. The results are summarized in Table I. They show no effect of 4 min of stimulation at a cycle length of $1,400 \mathrm{~ms}$ or of stretching the muscle to the point at which it develops $50 \%$ of its maximal steady state force on the $\alpha_{K}^{1}$ measurements. These results do not rule out the possibility that $\alpha_{\mathrm{K}}^{1}$ was different from the control value at the 4th min of stimulation but rapidly recovered before our measurements could detect the change. With this proviso, the results confirm that a positive inotropic effect of ouabain can be seen in the absence of change in $\alpha_{\mathrm{k}}^{\mathrm{i}}$.

Signs of toxicity and correlation with ouabain effects on $\alpha_{K}^{i}$. Evidence of glycoside intoxication was seen at ouabain concentrations of $0.1,1$, and $10 \mu \mathrm{M}$. At 0.1 and $1 \mu \mathrm{M}$, the sequential development of toxic signs was slow enough to be examined and correlated with changes in $\alpha_{\mathrm{k}}^{1}$. Table II lists the temporal development of toxic signs at these two concentrations. The only toxic sign seen at $0.1 \mu \mathrm{M}$ ouabain is triggered automaticity. At this concentration no change in $\alpha_{k}^{1}$ was noted (Fig. 4). Fig. 6 illustrates that development of triggered automaticity occurred before $\alpha_{\mathrm{K}}^{1}$ has changed. Similarly, at $1 \mu \mathrm{M}$ ouabain, Table II shows that triggered automaticity develops at $30 \mathrm{~min}$ exposure which, as comparison with Fig. 4 shows, was before $\alpha_{\mathrm{k}}^{\mathrm{i}}$ changed.

A second toxic sign is the conversion of the normal contractile force response to repetitive stimulation from an ascending to descending staircase. An ex- 


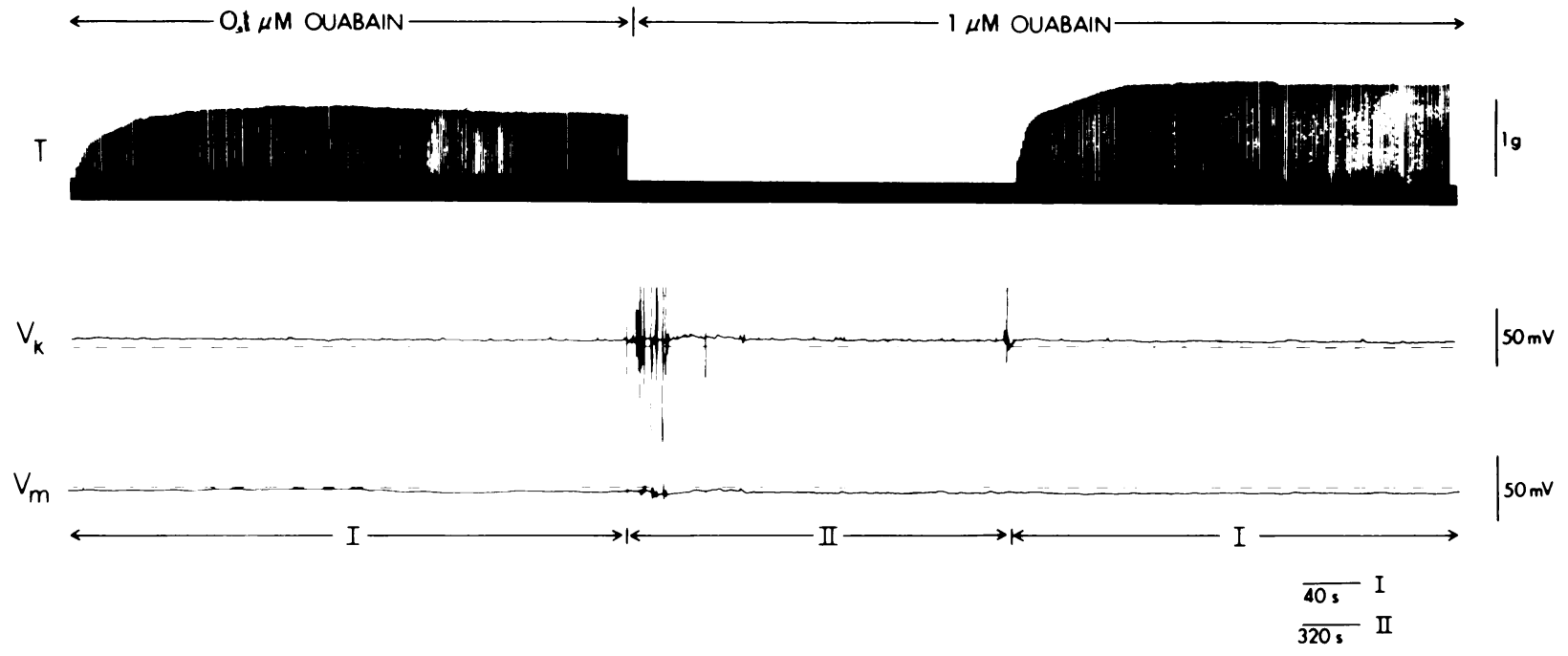

FIGURE 5 Continuous measurement of $\alpha_{\mathrm{k}}^{\mathrm{i}}$ during development of positive inotropy. Contractile force $(T), V_{K}$, and $V_{m}$ are recorded during switch in superfusate from one containing 0.1 to one containing $1 \mu \mathrm{M}$ ouabain. Positive inotropic response is evident but neither $\mathrm{V}_{\mathrm{h}}$ nor $\mathrm{V}_{\mathrm{m}}$ changes, implying no change in $\alpha_{\mathrm{K}}^{\mathrm{i}}$. Dashed lines are reference potentials for analyzing the figure.

ample is shown in Fig. 7. A control recording of contractile force during 4 min of stimulation shows the normal ascending staircase (A). Response is enhanced after $90 \mathrm{~min}$, when it has become mixed, with an initial increase in force followed by a decrease (B). Response after $120 \mathrm{~min}$ exposure is monotonically decreasing (D). The toxic staircase response entered in Table II refers to this monotonic decrease in force. A comparison of its time of onset with time of onset of effects on $\alpha_{\mathrm{k}}^{\mathrm{i}}$ shows (Fig. 4) the toxic staircase response did not occur before decreases in $\alpha_{\mathrm{k}}^{\mathrm{i}}$. The appearance of a toxic staircase regularly correlates with the development of aftercontractions (AC) to short trains of rapid stimulation. Fig. 8B shows an example in which $\mathrm{AC}$ are elicited at the time of first appearance of the toxic staircase. The same result was seen in each of three preparations for which AC were checked.

TABLE I

Potassium Activity and Contractile Force Measured in the Same Muscle*

\begin{tabular}{lccc}
\hline \multirow{4}{*}{ Time of ouabain exposure } \\
\cline { 2 - 4 } & 0 & 30 & 60 \\
\hline \multirow{3}{*}{$\alpha_{\mathrm{k}}^{\mathrm{i}}$} & 91.1 & 93.4 & 91.1 \\
& $(5.1) \frac{\min }{2} \mathrm{~T} / \mathrm{TC}$ & $(3.6)$ & $(2.8)$ \\
& 1.0 & 1.3 & 1.4 \\
& - & $(0.1)$ & $(0.2)$ \\
\hline
\end{tabular}

* Entries give means derived from four experiments. $\$$ Numbers in parentheses are SE.
The terminal signs of toxicity are inexcitability and muscle contracture. Inexcitability is first seen after $120 \mathrm{~min}$ exposure to $1 \mu \mathrm{M}$ ouabain (Table II). By 150 min exposure, all muscles exposed to $1 \mu \mathrm{M}$ are inexcitable. Contracture develops at $10 \mu \mathrm{M}$ ouabain (Fig. 8C). $\alpha_{\mathrm{K}}^{\mathrm{i}}$ has fallen markedly by the time inexcitability and contracture develop. Thus, from the electrode withdrawal record of Fig. 8C, an $\alpha_{\mathrm{k}}^{\mathrm{i}}$ of 62.3 $\mathrm{mM}$ can be calculated as compared with the $\alpha_{\mathrm{K}}^{\mathrm{i}}$ value of $79.1 \mathrm{mM}$ calculated from the control records Fig. 8A.

Correlation of resting potential and action potential duration changes with positive inotropic and toxic effects. Because a component of resting potential arises from the electrogenicity of $\mathrm{Na}-\mathrm{K}$ transport (22), resting potential was measured during ouabain exposure. APD was another electrophysiological quantity monitored because electrogenic Na-K pumping can alter action potential duration (23), and because cardiac glycosides can affect the slow inward current, which is a determinant of APD (24). Fig. 9 shows the measurements of resting potential for the ouabain concentrations and times examined. The threshold for change in resting potential is $1 \mu \mathrm{M}$ ouabain at which concentration we noted changes in resting potential at $60 \mathrm{~min}$ of exposure and thereafter. Resting potential changes are dissociated from the onset of positive inotropy and are a relatively late sign of toxicity. Toxic staircase, AC, and arrhythmias can be seen in the absence of any effect on $V_{m}$.

Fig. 10 shows results of measurements of APD at the take-off potential level. Results are expressed as values relative to those obtained before exposure to ouabain. The absolute values of the control period 
TABLE II

Time-course of Development of Toxic Effects of Ouabain*

\begin{tabular}{|c|c|c|c|c|c|c|c|c|c|c|}
\hline \multirow{2}{*}{$\begin{array}{c}\text { Ouabain } \\
\text { concentration }\end{array}$} & \multirow[b]{2}{*}{ Toxic sign } & \multicolumn{7}{|c|}{ Exposure time } & \multirow{2}{*}{$\begin{array}{l}\text { Number of pairs } \\
\text { showing sign } \\
\text { at some time }\end{array}$} & \multirow{2}{*}{$\begin{array}{c}\text { Total numbe } \\
\text { of pairs } \\
\text { examined }\end{array}$} \\
\hline & & 0 & 30 & 60 & 90 & 120 & 150 & 180 & & \\
\hline \multicolumn{11}{|c|}{$\min$} \\
\hline \multirow[t]{3}{*}{$0.1 \mu \mathrm{M}$} & $\begin{array}{l}\text { Triggered } \\
\text { automaticity }\end{array}$ & 0 & 0 & 0 & 0 & 3 & 2 & 2 & 3 & 4 \\
\hline & Toxic staircase & 0 & 0 & 0 & 0 & 0 & 0 & 0 & 0 & \\
\hline & Inexcitability & 0 & 0 & $\mathbf{0}$ & $\mathbf{0}$ & 0 & 0 & 0 & 0 & \\
\hline \multirow[t]{3}{*}{$1 \mu \mathrm{M}$} & $\begin{array}{l}\text { Triggered } \\
\text { automaticity }\end{array}$ & 0 & 5 & 5 & 5 & 1 & 0 & 0 & 5 & 5 \\
\hline & Toxic staircase & 0 & 0 & 1 & 3 & 3 & 0 & 0 & 5 & \\
\hline & Inexcitability & 0 & 0 & 0 & 0 & 2 & 5 & 5 & 5 & \\
\hline
\end{tabular}

* Entries give number of fibers showing the toxic sign at a given time.

measurement of APD are given in Table III. Effects of ouabain are markedly concentration-dependent. At lower concentrations, ouabain prolongs the action potential, whereas at higher concentrations a shortening is seen. The lengthening effect is ambiguous at $1 \mathrm{nM}$ and fully developed at $10 \mathrm{nM}$ ouabain. At $1 \mu \mathrm{M}$ ouabain the shortening effect is apparent. At the intermediate concentration of $0.1 \mu \mathrm{M}$ the transition from action potential prolongation to shortening is manifested as little change in duration. Of the quantities we measured, only APD changes at a positive inotropic, subtoxic ouabain concentration ( $10 \mathrm{nM})$. At $1 \mathrm{~h}$ of exposure the action potential prolongation is significant $(P<0.05)$.

Correlation of $\alpha_{K}^{e}$ with positive inotropic and toxic effects. Since $\alpha_{\mathrm{K}}^{\mathrm{e}}$ would be expected to change if Na$\mathrm{K}$ pump rate were accelerated or decreased, $\alpha_{\mathrm{K}}^{\mathrm{e}}$ was measured during exposure to ouabain. As previously mentioned, measurements of $\alpha_{\mathrm{K}}^{e}$ are made by impaling a double-barrel electrode through the first cell layer into the first intercellular space. Fig. 11A shows a record of this process. As the slow healing over occurs,
A.
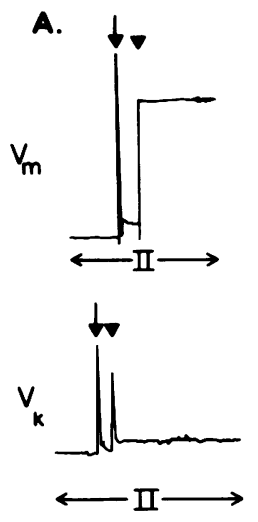

B.

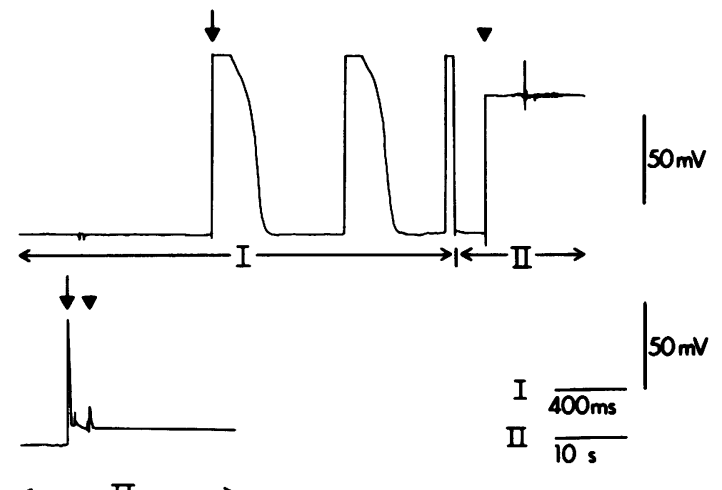

T

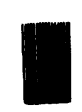

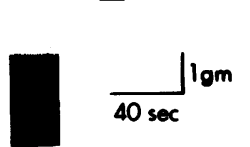

FIGURE 6 Records showing that automaticity develops before changes in $\alpha_{\mathrm{K}}^{\mathrm{l}}$ in cat ventricular muscles exposed to ouabain. Control $V_{m}, V_{K}$, and contractile force (T) measurements (A). Same measurements made after exposure to $1 \mu \mathrm{M}$ ouabain. Arrows denote stimulated action potential. Arrowheads denote electrode withdrawal from cell. Two spontaneous excitations following the stimulated one are evident (B). 
A

CONTROL

B
$1 \mu \mathrm{M}$
OUABAIN
for $30 \mathrm{~min}$.

C
$1 \mu \mathrm{M}$
OUABAIN
for $90 \mathrm{~min}$.

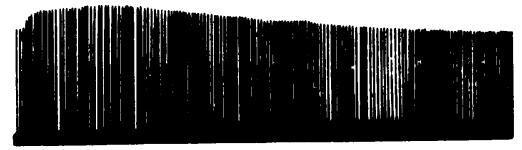

D
$1 \mu \mathrm{M}$
OUABAIN

for $120 \mathrm{~min}$

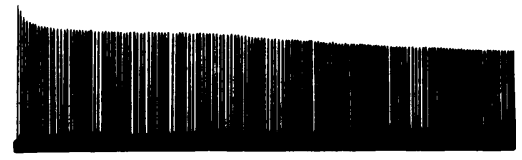

$\lg$

FIGURE 7 Development of toxic staircase response in a cat ventricular muscle exposed to $1 \mu \mathrm{M}$ ouabain. Control ascending staircase (A). Positive inotropic response to ouabain (B). Transition phase, from positive inotropic response to toxic staircase response (C). Toxic staircase response (D).

the level of the recording drifts closer to that of the extracellular space and eventually stabilizes. The value of $\alpha_{\mathrm{K}}^{\mathrm{e}}$ calculated from the $\mathrm{V}_{\mathrm{m}}$ and $\mathrm{V}_{\mathrm{K}}$ baselines recorded before impalement is $4.8 \mathrm{mM}$. After a further $10 \mathrm{~min}$ of healing over has passed, a control record of force has been taken. In Fig. 11B, records are shown after $3 \mathrm{~h}$ of exposure to $10 \mathrm{nM}$ ouabain caused no change in $\alpha_{\mathrm{k}}^{\mathrm{e}}$. A slow drift of $-8.5 \mathrm{mV}$ has occurred in both $V_{K}$ and $V_{m}$ levels in the superfusate at the beginning (A) and end (B) of the experiment. The reference level for $V_{K}$ and $V_{m}$ at any point in Fig. 11B is derived from the electrode withdrawal level by multiplying the time from that point until electrode withdrawal by the drift rate of $2.1 \mathrm{mV} / \mathrm{h}$. This assumed a linear drift rate. Fig. 11B shows that at a time when toxicity in the form of arrhythmia and AC has occurred, $\alpha_{\mathrm{K}}^{\mathrm{e}}$ is higher than control $(6.0 \mathrm{mM})$. Fig. $12 \mathrm{~A}$ shows a continuous record of $\alpha_{\mathrm{K}}^{\mathrm{e}}$ during a change in superfusate from one containing $0.1 \mu \mathrm{M}$ ouabain to one containing $1 \mu \mathrm{M}$ ouabain. No change in $\alpha_{\mathrm{K}}^{\mathrm{e}}$ from the control value had occurred during exposure to $0.1 \mu \mathrm{M}$ ouabain. Fig. 5 demonstrated that the change from 0.1 to $1 \mu \mathrm{M}$ ouabain has a large positive inotropic effect. The lack of change in $V_{K}$ or $V_{m}$ traces in
Fig. 12A implies no elevation $\alpha_{\mathrm{K}}^{\mathrm{e}}$ at the time of positive inotropic effect. When the superfusate is changed to one containing $10 \mu \mathrm{M}$ ouabain, however, a progressive increase in $\alpha_{\mathrm{K}}^{\mathrm{e}}$ is evident, manifested by the upward movement of the $\mathrm{V}_{\mathrm{K}}$ trace.

Correlation of percentage cell volume with positive inotropic and toxic effects of ouabain. In Fig. 13, percentage of cell volume measurements are shown during control, drug exposure, and washout periods for $10 \mathrm{nM}$ (A) and $1 \mu \mathrm{M}$ (B) ouabain in two separate muscles. At neither drug concentration has cell volume been affected. At the far right (A and B) are shown the transpartition voltage drops with muscles absent from the partition hole. From these measurements the percentage of cell volumes for the muscles are $70.2 \%(\mathrm{~A})$ and $71.1 \%(\mathrm{~B})$, respectively.

\section{DISCUSSION}

Pump stimulation/inhibition in relation to positive inotropic effect. The mechanism of positive inotropic effect of cardiac glycosides is unresolved, but major attention continues to be given to the idea that changes in intracellular ionic composition either through $\mathrm{Na}$ $\mathrm{K}$ pump stimulation or inhibition are responsible. Hajdu and Leonard (25) advanced the early proposal that net losses of cellular potassium are a prerequisite for the positive inotropic effect of glycosides. Langer and Serena (9) later showed that in rabbit ventricular muscle, positive inotropy is always associated with cellular gains of sodium and losses of potassium and went on to attribute mechanistic significance to the gains in sodium. Müller's (8) results in cow ventricular muscle reinforce Langer's without necessarily supporting his interpretations. Most recently, in a study of sheep Purkinje fiber, Eisner and Lederer (26) always found a decrease in an electrogenic pump current attributed to the Na-K pump at times of positive inotropic effect of strophanthidin. All these workers' results indicate $\mathrm{Na}-\mathrm{K}$ pump inhibition at the time of positive inotropic effect. Other advocates of this hypothesis $(2,13)$ have emphasized that pump inhibition need not be reflected in altered intracellular milieu because of a reserve pool of $\mathrm{Na}-\mathrm{K}$ pumps that may exist (4).

In many other studies, evidence points to $\mathrm{Na}-\mathrm{K}$ pump stimulation at the time of onset of positive inotropy. Noack et al. (3) found an increase in $[\mathrm{K}]_{\mathrm{i}}$ at the time of positive inotropy in guinea pig atria. RuizCeretti et al. (10) showed that a similar effect occurs in rabbit ventricles. Godfraind (27-30) showed that low concentrations of ouabain and digoxin that increase contractile force also stimulate ${ }^{42} \mathrm{~K}$ uptake by and $\mathrm{Na}$ content of guinea pig atria. In sheep Purkinje fibers, $0.1 \mathrm{M}$ ouabain produced depletion of cleft potassium as judged from reversal potential for the $i_{K_{2}}$ current, again suggesting pump stimulation (20). 


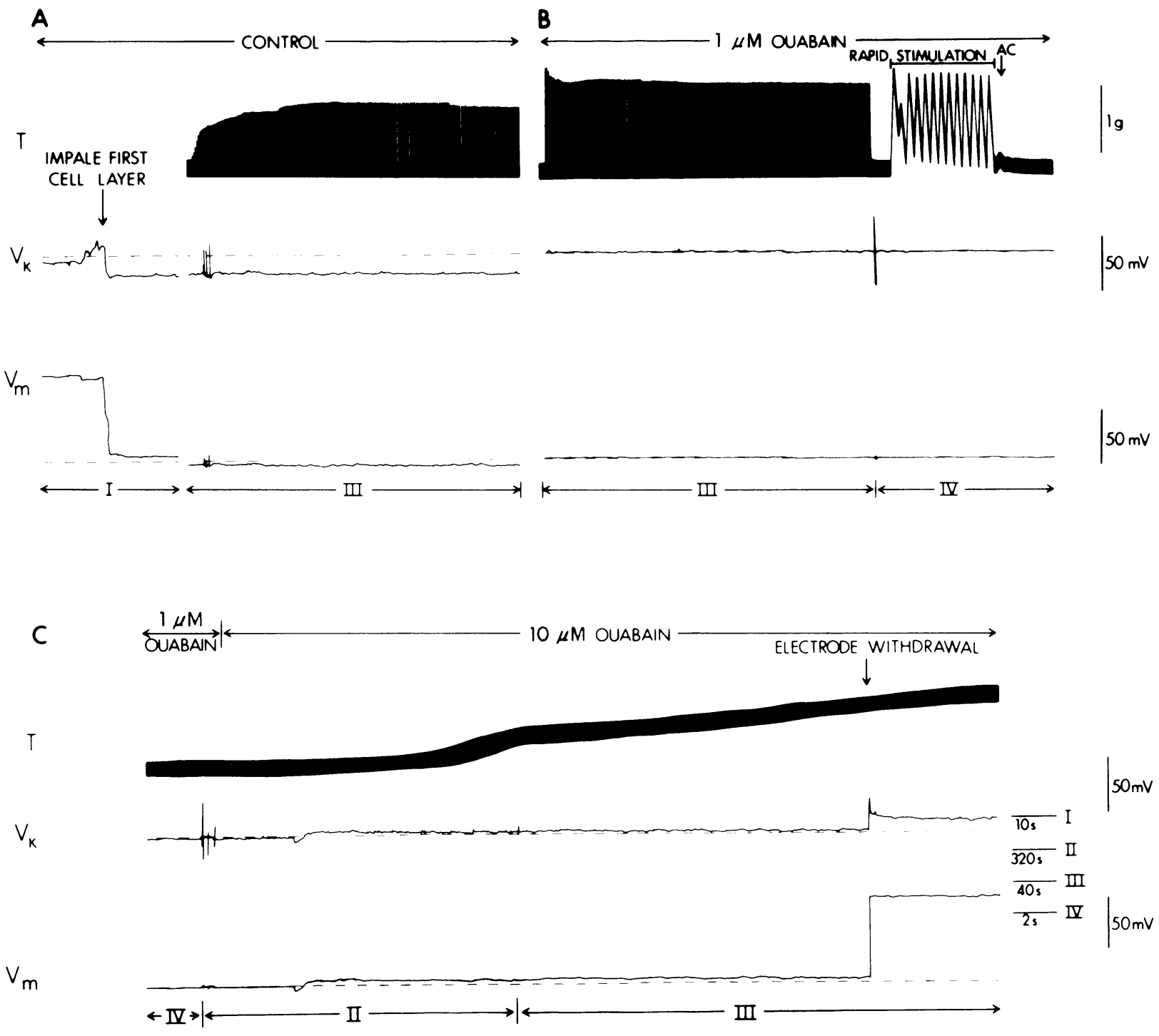

Figure 8 Simultaneous measurement of $\alpha_{\mathrm{K}}^{\mathrm{i}}$ and contractile force during exposure to toxic ouabain concentrations. Control recordings of contractile force $(T), V_{K}$, and $V_{m}(A)$. Recordings after $120 \mathrm{~min}$ of exposure to $1 \mu \mathrm{M}$ ouabain. Illustration that at the time of development of the toxic staircase response, $\mathrm{AC}$ can be elicited (B). In continuation, development of inexcitability, contracture, and decrease in $\alpha_{\mathrm{K}}^{\mathrm{i}}$ during exposure to $10 \mu \mathrm{M}$ ouabain is seen $(\mathrm{C})$. Attempts were made to stimulate the muscle but no response can be seen. Dashed lines are reference potentials for analyzing the figure.

The indices of $\mathrm{Na}-\mathrm{K}$ pump function examined in this study are $\alpha_{\mathrm{K}}^{\mathrm{e}}$ and $\alpha_{\mathrm{K}}^{\mathrm{i}}$. These indices have certain advantages over the kinetic indices from tracer flux studies (9) or biochemical indices from enzyme isolation studies (31). In particular, all tracer flux techniques rely on compartmental models that often fail to reflect the known morphological complexity of cardiac tissue (32). Enzyme isolation studies, on the other hand, unavoidably disrupt the membrane environment that may be important in the pumping mechanism.
Measurements of $\alpha_{\mathrm{K}}^{\mathrm{e}}$ and $\alpha_{\mathrm{K}}^{\mathrm{i}}$ are relatively free of these problems, but they have their own disadvantages. Measurements of $\alpha_{\mathrm{K}}^{\mathrm{i}}$ may be distorted (lowered) by electrode-induced cell damage (21). In measurements of $\alpha_{\mathrm{K}}^{\mathrm{e}}$, the sensitivity will be blunted by the unavoidable distortion of the spaces by the electrode tip. In addition, if cells in the vicinity of the tip are killed, a buffer zone will be created between the true extracellular space and the space sampled by the electrode tip. There is little doubt that these drawbacks cause 
measurements of $\alpha_{\mathrm{k}}^{\mathrm{e}}$ to underestimate and lag behind the true changes. Unfortunately, no method exists at present to independently assess $\alpha_{\mathrm{K}}^{\mathrm{e}}$.

It is within the context of these limitations that we interpret our measurements to favor the independence of positive inotropic effect of ouabain from inhibition of cellular $\mathrm{Na}-\mathrm{K}$ pump rate. Unmistakable increases in contractile force were observed at a time when $\alpha_{\mathrm{K}}^{\mathrm{e}}$ had not increased nor $\alpha_{\mathrm{K}}^{\mathrm{i}}$ decreased. This interpretation is compatible, however, with the inhibition of particular Na-K pumps on the cell membrane, since a reserve pool of pumps may exist (4, 33). Our results at higher ouabain concentrations agree with those of others in showing that larger positive inotropic effects do accompany inhibition of cellular Na-K pump rate. For the ouabain concentrations we sampled, the greater positive inotropy associated with pump inhibition was always associated with toxicity. Others, however, have reported positive inotropic effects associated with inhibition in rate of cellular $\mathrm{Na}-\mathrm{K}$ pumping and without evidence of toxicity (13). Our results also agree with those of other in vitro studies in finding a positive inotropic effect without toxicity of ouabain concentrations that are clearly toxic in intact animals (34).

Our results also favor independence of positive inotropic effect from stimulation of cellular $\mathrm{Na}-\mathrm{K}$ pump rate. The evidence to support this statement is necessarily weaker, because the reported stimulatory effects of glycosides have been small and sometimes transient. Nevertheless, we never saw a decrease in $\alpha_{\mathrm{K}}^{\mathrm{e}}$ to support a hypothesized Na-K pump stimula-

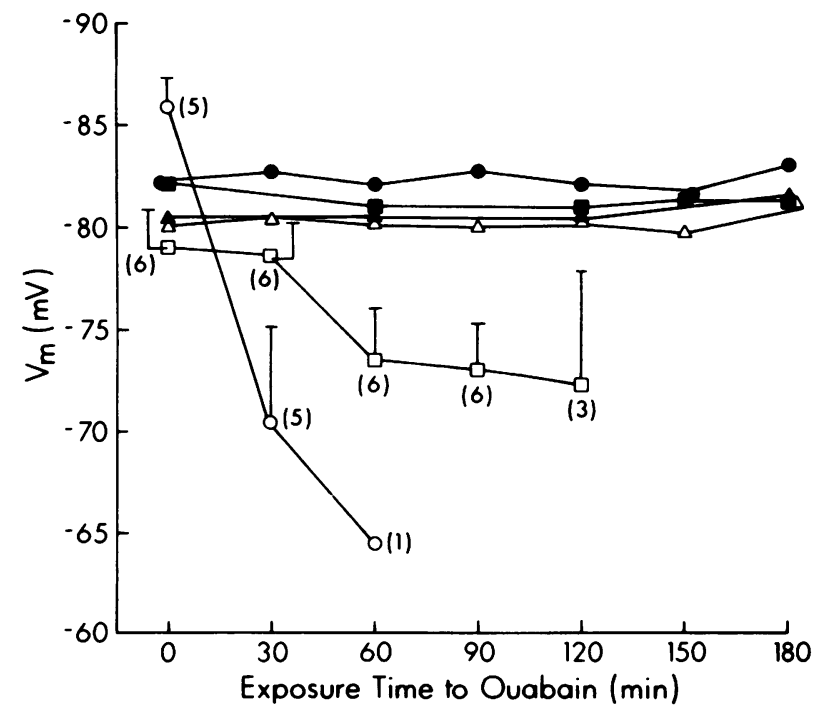

Figure 9 Pooled measurements of resting potential measured before and after exposure to ouabain. Filled triangles - control; open circles $-10 \mu \mathrm{M}$; open squares $-1 \mu \mathrm{M}$; open triangles$0.1 \mu \mathrm{M}$; filled circles - $10 \mathrm{nM}$; filled squares $-1 \mathrm{nM}$ ouabain.
A

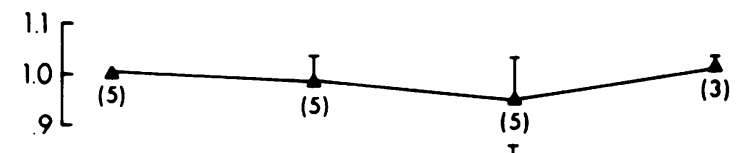

B

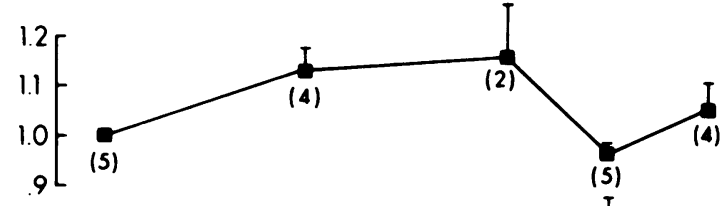

C

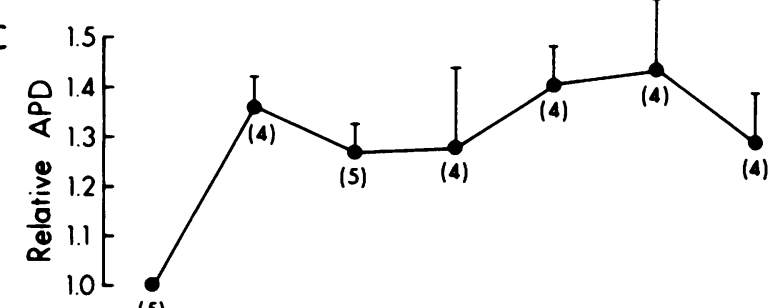

(5)
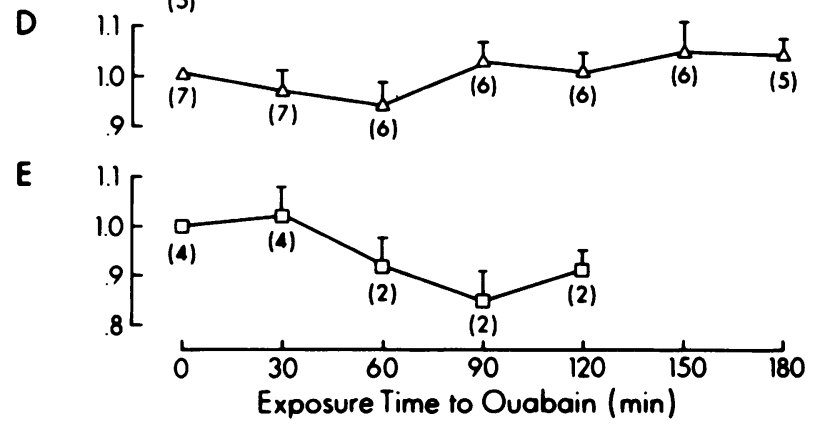

Figure 10 Action potential duration from cat ventricular muscles exposed to different ouabain concentrations. Control muscles not exposed to ouabain (A). B, C, D, and E correspond to muscles exposed to $1 \mathrm{nM}, 10 \mathrm{nM}, 0.1 \mu \mathrm{M}$, and $1 \mu \mathrm{M}$ ouabain, respectively.

tion. The absence of change in $\alpha_{\mathrm{K}}^{\mathrm{e}}$ in our study conflicts with the inferences of Cohen et al. (20), who found that low concentrations of ouabain hyperpolarized the reversal potential for $i_{\mathbf{K}_{2}}$ in sheep Purkinje fibers. Their indirect data suggested a decrease in $\alpha_{\mathrm{k}}^{\mathrm{e}}$. The

TABLE III

Control Period Determinations of APD* for Experiments Expositing Papillary Muscles to Different Concentrations of Ouabain

\begin{tabular}{lrrrrr}
\hline & \multicolumn{5}{c}{ Ouabain concentration } \\
\cline { 2 - 6 } & 0 & $1 \mathrm{nM}$ & $10 \mathrm{nM}$ & $0.1 \mu \mathrm{M}$ & $1 \mu \mathrm{M}$ \\
\hline Control period & & & & & \\
$\quad$ action potential & & & & & \\
$\quad$ duration, $m s$ & 352 & 333 & 332 & 297 & 291 \\
SEM & 14 & 21 & 35 & 11 & 16 \\
$n \ddagger$ & 5 & 5 & 5 & 7 & 4 \\
\hline
\end{tabular}

* APD was measured at the take-off potential.

\$ Total number of muscle pairs examined. 
A.

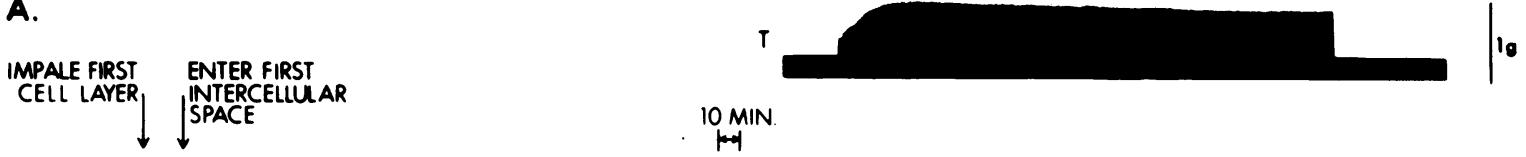

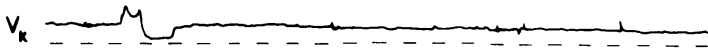
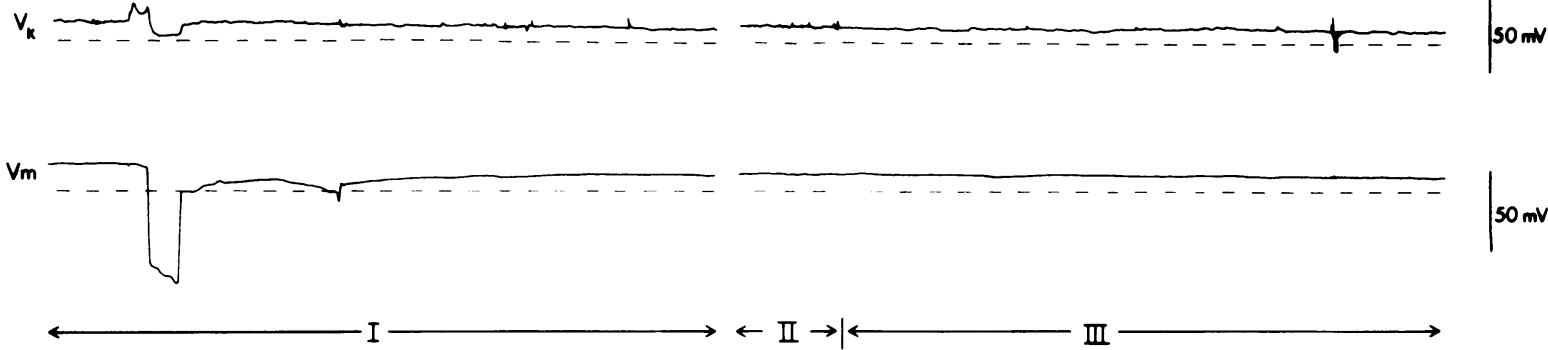

$\leftarrow$ II $\rightarrow \mid$

B.
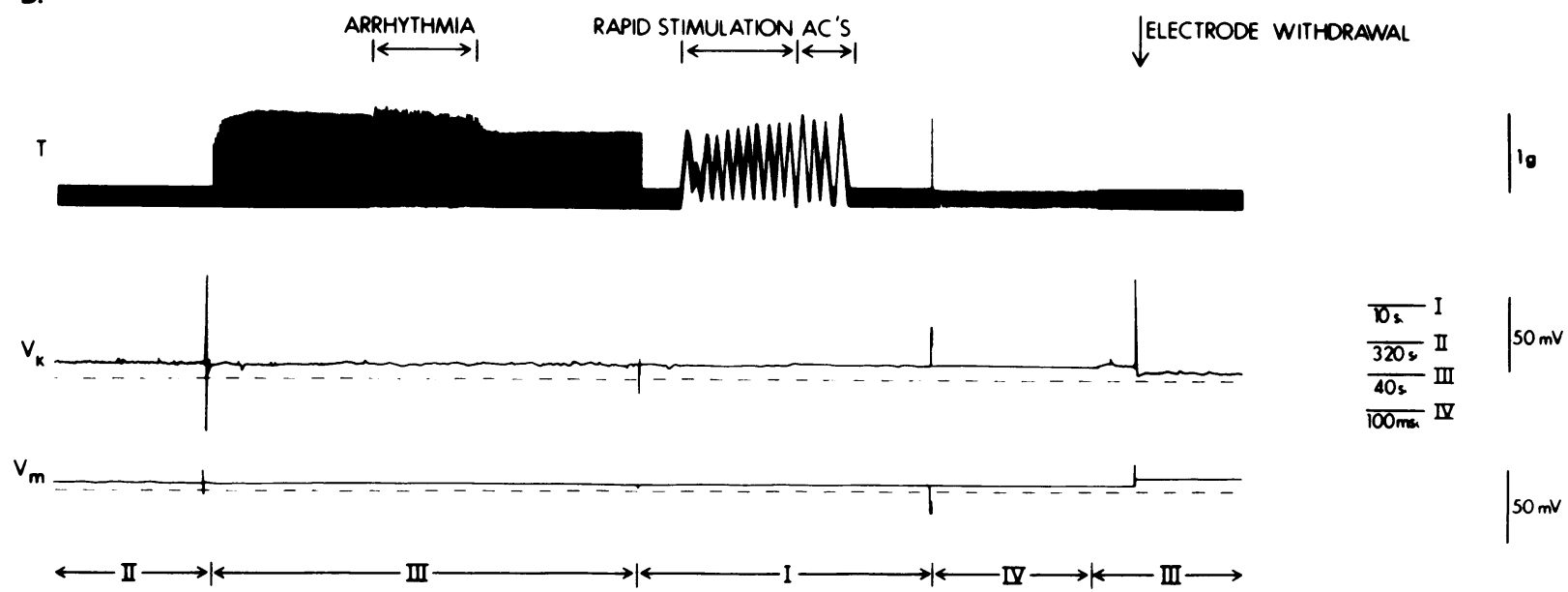

FigURE 11 Continuous measurement of $\alpha_{\mathrm{K}}^{\mathrm{e}}$ and contractile force (T) before and during exposure of cat ventricular muscle to $1 \mu \mathrm{M}$ ouabain. Illustration of technique of measuring $\alpha_{\mathrm{K}}^{\mathrm{e}}$. The electrode impales the first cell layer and is advanced until the large intracellular resting potential $\left(\mathrm{V}_{\mathrm{m}}\right.$ trace $)$ is lost. After a further $10 \mathrm{~min}$ of stabilization, control force, $V_{\mathrm{K}}$ and $\mathrm{V}_{\mathrm{m}}$ are recorded (A). Recordings after $3 \mathrm{~h}$ exposure to $10 \mathrm{nM}$ ouabain and a further $1 \mathrm{~h}$ to $1 \mu \mathrm{M}$ ouabain (B). Analysis of records given in text. Dashed lines provide reference potentials for analyzing the figure.

following distinctions, however, make it difficult to compare the two studies: $(a)$ we studied ventricular muscle from cat, which may respond to ouabain in a different manner than Purkinje fiber from sheep. (b) the average cleft width in ventricular muscle is $>0.5$ $\mu \mathrm{m}$ (35), whereas an average width of $0.04 \mu \mathrm{m}$ has been reported in sheep Purkinje fibers (36). The larger size in ventricular muscle would dilute the effect that any change in pump rate would have on the potassium activity of the cleft space. Finally, as previously mentioned, impalement of the electrode into the cleft space distorts and enlarges it and lowers the sensitivity of the measured $\alpha_{\mathrm{K}}^{\mathrm{e}}$ as an index of change in pump rate. The absence of change in a $\alpha_{\mathrm{K}}^{\mathrm{e}}$ also argues against the mechanism proposed by Greenspan and Morad (11), whereby intracellular potassium is extruded in exchange for extracellular calcium. This mechanism would predict that $\alpha_{\mathrm{K}}^{\mathrm{e}}$ should rise at positive inotropic concentration of ouabain.

Our results support mechanisms of positive inotropic effect that are independent of $\mathrm{Na}-\mathrm{K}$ pump effects $(24,33,37)$ or which feature perturbations of $\mathrm{Na}$-, $\mathrm{K}$ pump rate within single cardiac cycles, but not in pump rate averaged over many cardiac cycles (38). Of particular interest is the increase in slow inward current found by Weingart et al. (24) in sheep Purkinje fibers exposed to $20 \mathrm{nM}$ strophanthidin. We found that APD in cat ventricular muscle is prolonged at 10 
A

$k-0.1 \mu \mathrm{M}$ OUABAIN $\longrightarrow * \longrightarrow 1 \mu \mathrm{M}$ OUABAIN $\longrightarrow$
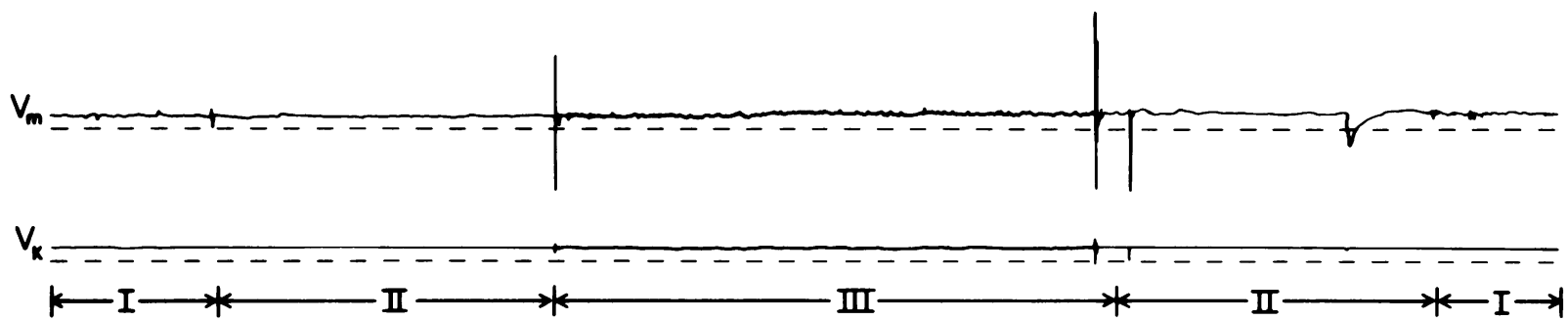

B
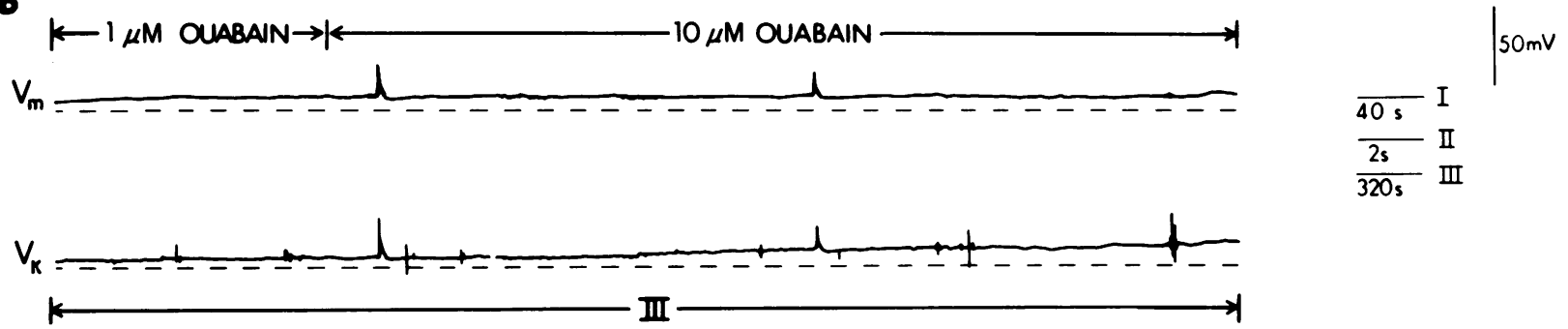

FIGURE 12 Measurement of potassium activity in the extracellular space during exposure of cat ventricular muscles to ouabain. The absence of change in $V_{K}$ or $V_{m}$ traces when the muscle is initially exposed to $1 \mu \mathrm{M}$ ouabain implies no change in $\alpha_{\mathrm{K}}^{0}(\mathrm{~A})$. Soon after switching superfusate to one containing $10 \mu \mathrm{M}$ ouabain, the $\mathrm{V}_{\mathrm{K}}$ trace depolarizes, indicating increase in $\alpha_{\mathrm{K}}^{\mathrm{e}}$. Dashed lines are reference potentials for analyzing the figure (B).

$\mathrm{nM}$ ouabain. In a study of rabbit ventricular muscle, Ruiz-Ceretti et al. (10) showed a lengthening of APD at the time of first positive inotropic effect. A similar result had been found earlier in sheep ventricular muscle when exposed to strophanthidin (39). Such effects would be compatible with Weingart et al.'s (24) results in Purkinje fibers and suggests that similar voltage clamp data will be found in ventricular muscle.

The decrease in APD that we observed after 60 or more min of exposure to $1 \mu \mathrm{M}$ ouabain is similar to the results of Prasad et al. (40) in monkey ventricular muscle and to the late phase results of $1.4 \mu \mathrm{M}$ ouabain exposure in sheep ventricular muscle seen by Kassebaum (39). Because the time course parallels that of the increase in $\alpha_{\mathrm{K}}^{\mathrm{e}}$, it is tempting to attribute the action potential shortening to the higher $\alpha_{\mathrm{k}}^{\mathrm{e}}$, which is known to accelerate repolarization (41). The lack of effect of $0.1 \mu \mathrm{M}$ ouabain on APD may represent a crossover from the lengthening effect of low ouabain concentrations that do not inhibit the $\mathrm{Na}-\mathrm{K}$ pump to the shortening effect of higher concentrations that do inhibit the pump.

Glycoside effects on cell volume. Leaf (42) has suggested that the active transport of sodium and potassium is important in regulating cell volume. As an agent that can stimulate and inhibit Na-K pumping under various conditions, ouabain can conceivably change cell volume and complicate the interpretation of $\alpha_{\mathrm{K}}^{\mathrm{i}}$ measurements. Previous studies of this possibility using extracellular space markers have yielded different results. In surperfused guinea pig atrial muscle, Noack et al. (3) found no differences in percentage of cell volume of control preparations and preparations exposed to $0.1 \mu \mathrm{M}$ ouabain. Pine et al. (43) observed no changes in cell volume in guinea pig ventricular or atrial slices exposed to $1 \mathrm{mM}$ ouabain. In contrast, Ruiz-Ceretti et al. (10) found that exposure of perfused rabbit ventricles to $0.5 \mu \mathrm{M}$ ouabain produced a $7 \%$ increase in cell volume. Similar increases

A

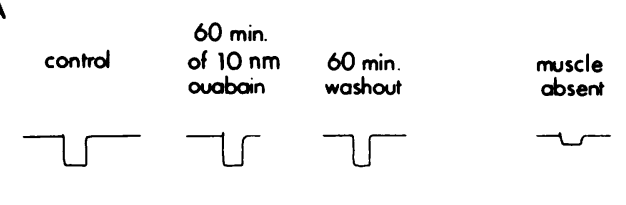

B

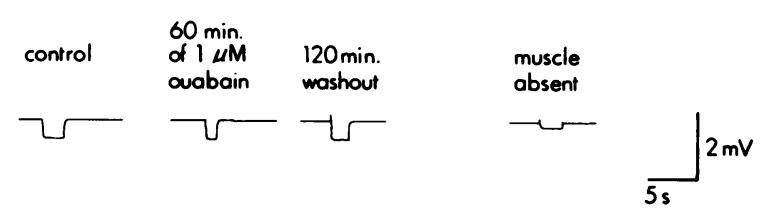

Figure 13 Measurements of percentage of cell volume before, during, and after exposure to two ouabain concentrations. Measurements in a muscle exposed to $10 \mathrm{nM}$ ouabain (A). Measurements in a muscle exposed to $1 \mu \mathrm{M}$ ouabain. In neither case does cell volume change (B). 
were noted in the arterially perfused interventricular septum of the rabbit exposed to $2-5 \mu \mathrm{M}$ ouabain (44). The discrepancies between these studies may reflect tissue-specific differences in response of cell volume to ouabain or may reflect differences in experimental conditions.

Our results, obtained using an electrophysiological method, show that at inotropic and toxic concentrations of ouabain, no change in cell volume occurs. Taken in conjunction with the lack of effect of inotropic concentrations on $\alpha_{\mathrm{k}}^{1}$, this information might be taken to imply disagreement between our results and those of others who have observed decreases in $[\mathrm{K}]_{\mathrm{i}}$ in ventricular muscles studied with tracer flux techniques $(8,9)$. It may be, however, that ouabain affects the potassium activity coefficient, $\gamma_{\mathrm{K}}$, as for example cooling is known to do (45). In this case, no parallelism between effects on $\alpha_{\mathrm{K}}^{\mathrm{L}}$ and $[\mathrm{K}]_{\mathrm{i}}$ would be expected. The physical interpretation of a change in $\gamma_{\mathrm{K}}$ could either be a redistribution of potassium between cytoplasmic pools or a change in the properties of surfaceassociated water (46).

It would be attractive to relate our findings regarding $\alpha_{\mathrm{k}}^{\prime}$ to results on potassium content obtained by tracer flux or flame photometry techniques in other earlier studies. We would re-emphasize, however, that unless $\alpha_{\mathrm{K}}^{1}, \mathrm{~K}$ content, and cell volume measurements are made in the same tissue, such comparisons can only be speculative. As Ellis (5) and Noble (47) have pointed out, there are tissue specific differences in response to drugs. It appears that this generality applies to ouabain in particular. For instance, atrial tissue is reported to accumulate potassium at low, positive inotropic concentrations of ouabain $(3,28-30)$, whereas ventricular muscle is reported to consistently lose potassium $(8,9)$. In none of these studies was the drug effect on cell volume addressed, making predictions of $\alpha_{\mathrm{K}}^{\mathrm{d}}$ changes based on the potassium content results indeterminate (21). Another confounding variable making extensive comparisons difficult are the well-known species-dependent differences in the effects of ouabain (48). For these reasons we have confined our comments to the two previous studies involving ventricular muscle $(8,9)$.

Concomitants of ouabain toxicity. The diverse electrical and mechanical manifestations of ouabain toxicity develop sequentially, signal different degrees of severity, and may have independent mechanisms. We have looked at onset of automaticity and toxic staircase, decrease in APD and resting potential, and onset of inexcitability and contracture and have correlated these events with the simultaneous drug effects on $\alpha_{k}^{1}, \alpha_{k}^{e}$, and cell volume. The earliest sign of toxicity was the appearance of triggered automaticity. Because right ventricular papillary muscles contain tracts of subendocardial and isolated deeper Purkinje cells (49), and because Purkinje cells are more susceptible to glycoside toxicity than ventricular cells $(50)$, it seems reasonable to ascribe this early toxic phase to ouabain's action on these cells. Consistent with this interpretation is the finding that $\alpha_{\mathrm{k}}^{\mathrm{i}}$ is unchanged in ventricular cells at this time and $\alpha_{\mathrm{K}}^{\mathrm{e}}$ unchanged as well. Positive inotropic effects, however, were always apparent at the time of these arrhythmias.

Toxicity to ventricular muscle cells appeared at a concentration of $1 \mu \mathrm{M}$ ouabain and was heralded by several signs that developed together. Electrically, $\alpha_{\mathrm{K}}^{\mathrm{e}}$ rose, $\alpha_{\mathrm{K}}^{\mathrm{i}}$ and resting potential fell, and APD decreased. Mechanically, a characteristic toxic staircase response to repetitive stimulation developed simultaneously with the ability to elicit AC. The electrical changes are internally consistent, because either or both a decrease in $\alpha_{\mathrm{k}}^{\mathrm{k}}$ and increase in $\alpha_{\mathrm{k}}^{\mathrm{e}}$, will depolarize the cell and because increases in $\alpha_{\mathrm{K}}^{e}$ reduce APD (51). Moreover, they resemble the changes seen in these quantities in Purkinje fibers exposed to toxic, although lower, concentrations of ouabain (52). Our contractile force measurements place the mechanical signs of toxicity in temporal relation to other toxic signs, but no new insights into mechanism are reached. The last and most severe signs of toxicity are electrical inexcitability of the preparation and mechanical contracture. Inexcitability appeared at a lower concentration $(1 \mu \mathrm{M})$ of ouabain than did contracture $(10 \mu \mathrm{M})$, but both signs always occur after $\alpha_{\mathrm{k}}^{\mathrm{k}}$ and resting potential have substantially decreased and $\alpha_{\mathrm{K}}^{\mathrm{e}}$ increased.

In summary, our results support the idea that the manifold effects of cardiac glycosides, both subtoxic and toxic, are mediated through several mechanisms that have distinct concentration thresholds. Action potential prolongation first develops at $10 \mathrm{nM}$ ouabain and a positive inotropic effect at $0.1 \mu \mathrm{M}$ ouabain, among the concentrations of ouabain tested. A change in $\alpha_{k}^{1}$ is not an inevitable concomitant of positive inotropic effect. Of the ouabain concentrations we tested, the lowest inhibiting $\mathrm{Na}-\mathrm{K}$ pump function $(1 \mu \mathrm{m})$ always produced toxicity. A sequence of electrical and mechanical toxic signs is discernible and correlates reproducibly with effects on $\alpha_{\mathrm{K}}^{\mathrm{l}}$ and $\alpha_{\mathrm{k}}^{\mathrm{e}}$.

\section{ACKNOWLEDGMENTS}

We thank Dr. A. G. Wallace for his continuing support and Renate Wend for typing this manuscript.

This investigation was supported by U. S. Public Health Service grants HL-19216, 17670, 07101, and 5-T32-GM 7105.

\section{REFERENCES}

1. Nayler, W. 1973. Effect of inotropic agents on canine trabecular muscle rendered highly permeable to calcium. Am. J. Physiol. 255: 919-924. 
2. Akera, T., and T. M. Brody. 1978. The role of $\mathrm{Na}^{+}, \mathrm{K}^{+}-$ ATPase in the inotropic action of digitalis. Pharmacol. Rev. 29: 187-220.

3. Noack, E., J. Felgenträger, and B. Zettner. 1979. Changes in myocardial $\mathrm{Na}$ and $\mathrm{K}$ content during development of cardiac glycoside inotropy. J. Mol. Cell. Cardiol. 11: 1189-1194.

4. Busse, F., H. Lüllman, and T. Peters. 1979. Concentration dependence of the binding of ouabain to isolated guinea pig atria. J. Cardiovasc. Pharmacol. 1: 687-698.

5. Ellis, D. 1977. The effects of external cations and ouabain on the intracellular sodium activity of sheep heart Purkinje fibers. J. Physiol. (London) 273: 211-240.

6. Blood, B. E. 1975. The influence of low doses of ouabain and potassium ions on sheep Purkinje fibre contractility. J. Physiol. (London) 251: 69-70P.

7. Lee, C. O., D. H. Kang, J. H. Sokol, and K. S. Lee. 1980. Relation between intracellular $\mathrm{Na}$ ion activity and tension of sheep cardiac Purkinje fibers exposed to dihydro-ouabain. Biophys. J. 29: 315-330.

8. Müller, P. 1965. Ouabain effects on cardiac contraction, action potential, and cellular potassium. Circ. Res. 18: 46-56.

9. Langer, G. A., and S. D. Serena. 1970. Effects of strophanthidin upon contraction and ionic exchange in rabbit ventricular myocardium: relation to control of active state. J. Mol. Cell. Cardiol. 1: 65-90.

10. Ruiz-Ceretti, E., J. P. Samson, I. Reisin, and O. F. Schanne. 1977. Ionic and electrical effects of ouabain on isolated rabbit hearts. J. Mol. Cell. Cardiol. 9, 51-61.

11. Greenspan, A. M., and M. Morad. 1975. Electromechanical studies on the inotropic effects of acetylstrophanthidin in ventricular muscle. J. Physiol. (Lond.) 253: 257-384.

12. Godfraind, T., and J. Ghysel-Burton. 1977. Binding sites related to ouabain-induced stimulation or inhibition of the sodium pump. The therapeutic mode of action of cardiac glycosides. Nature (Lond.). 265: 165-166.

13. Hougen, T. J., and T. W. Smith. 1978. Inhibition of myocardial monovalent cation active transport by subtoxic doses of ouabain in the dog. Circ. Res. 42: 856-863.

14. Kunze, D. L. 1977. Rate-dependent changes in extracellular potassium in rabbit atrium. Circ. Res. 41: 122-127.

15. Lee, C. O., and H. A. Fozzard. 1975. Activities of potassium and sodium ions in rabbit heart muscle. J. Gen. Physiol. 65: 695-708.

16. Houser, S. R., and A. R. Freeman. 1979. A simple method for volumetric measurements in isolated cardiac muscle. Am. J. Physiol. 263: H519-H534.

17. Ladle, R. O., and J. L. Walker. 1975. Intracellular chloride activity in frog heart. J. Physiol. (Lond). 251: 549-559.

18. Shieu, S. S., M..Korth, D. A. Lathrop, and H. A. Fozzard. 1980. Intra- and extracellular $\mathrm{K}^{+}$and $\mathrm{Na}^{+}$activities and resting membrane potential in sheep cardiac Purkinje strands. Circ. Res. 47: 692-700.

19. Lee, C. O., D. H. Kang, J. H. Sokol, and K. S. Lee. 1979. Relation between intracellular $\mathrm{Na}$ ion activity and positive ionotropic action of sheep cardiac Purkinje fibers. Biophys. J. 25: 1989.

20. Cohen, I., J. Daut, and D. Noble. 1976. An analysis of the actions of low concentrations of ouabain on membrane currents in Purkinje fibers. J. Physiol. (Lond.) 260: 75-103.

21. Browning, D. J., and H. C. Strauss. 1981. The effects of changes in stimulation frequency on intracellular potas- sium activity and cell volume in mammalian Purkinje and ventricular fibers. Am. J. Physiol. 240 (Cell Physiol. 9): C39-C55.

22. Thomas, R. C. 1972. Electrogenic sodium pump in nerve and muscle cells. Physiol. Rev. 52: 523-594.

23. Gadsby, D. C., and P. F. Cranefield. 1979. Electrogenic sodium extrusion in cardiac Purkinje fibers. J. Gen. Physiol. 73: 819-837.

24. Weingart, R., R. S. Kass, and R. W. Tsien. 1978. Is digitalis inotropy associated with enhanced slow inward calcium current? Nature (Lond.). 273: 389-392.

25. Hajdu, S., and E. Leondard. 1959. The cellular basis of cardiac glycoside action. Pharmacol. Rev. 11: 173-209.

26. Eisner, D. A., and W. J. Lederer. 1980. The relationship between sodium pump activity and twitch tension in cardiac Purkinje fibers. J. Physiol. (Lond.) 303: 475-494.

27. Godfraind, T. 1973. The therapeutic mode of action of cardiac glycosides. Arch. Int. Pharmacodyn. Ther. 206: 384-388.

28. Godfraind, T., and J. Ghysel-Burton. 1979a. Stimulation and inhibition of the sodium pump by cardioactive steroids in relation to their binding sites and their inotropic effect on guinea-pig isolated atria. Br.J. Pharmacol. 66: 175-184.

29. Godfraind, T., and J. Ghysel-Burton. 1979b. The cardioactive properties of SC 4453, a digoxin analogue with a $\mathrm{C}_{17}$ beta-pyridazine ring. Eur. J. Pharmacol. 60: 337-344.

30. Godfraind. T., and J. Ghysel-Burton. 1980. Independence of the positive inotropic effect of ouabain from the inhibition of the heart $\mathrm{Na}^{+}, \mathrm{K}^{+}$-pump. Proc. Natl. Acad. Sci. U. S. A. 77: 3067-3069.

31. Peters, T., R. H. Raben, and O. Wasserman. 1974. Evidence for dissociation between positive inotropic effect and inhibition of the $\mathrm{Na}^{+}, \mathrm{K}^{+}$-ATPase by ouabain, cassaine and then alkylating derivatives. Eur. J. Clin. Pharmacol. 26: 166-174.

32. Carmeliet, E., C. R. Horres, M. Lieberman, and J. S. Vereecke. 1977 Potassium permeability in the chick heart: change with age, external $K$, and valinomycin. In Developmental and Physiological Correlates of Cardiac Muscle. M. Lieberman, T. Sano, editors. Raven Press, N. Y.

33. Lüllman, H., T. Peters, and A. Ziegler. 1979. Kinetic events determining the effects of cardiac glycosides. Trends Pharmacol. Sci. 102-106.

34. Ku, D., T. Akera, C. L. Pew, and T. M. Brody. 1974. Cardiac glycosides: correlations among $\mathrm{Na}^{+}, \mathrm{K}^{+}$-ATPase, sodium pump and contractility in the guinea pig heart. Naunyn-Schmiedebergs Arch. Pharmacol. 285: 187-200.

35. Sommer, J. R., and E. A. Johnson. 1980. Ultrastructure of cardiac muscle. The Cardiovascular System. Vol. I. Handb. of Physiol. R. M. Berne, editor. American Physiological Society, Bethesda, Md. 113-186.

36. Hellam, D. C., and J. W. Studt. 1974. A core conductor model of the cardiac Purkinje fiber based on structural analysis. J. Physiol. (Lond.) 243: 637-660.

37. Dramane, K., P. Driot, and D. Garnier. 1971. Action de la ouabain sur les courants transmembranaires du myocarde sino-auriculaire de grenouille.J. Physiol. (Paris). 63: 43a.

38. Akera, T., R. T. Bennett, M. K. Olgaard, and T. M. Brody. 1976. Cardiac $\mathrm{Na}^{+}, \mathrm{K}^{+}$adenosine triphosphatase inhibition by ouabain and myocardial sodium: a computer simulation. J. Pharmacol. Exp. Ther. 199: 287-297.

39. Kassebaum, D. G. 1963. Electrophysiological effects of strophanthidin in the heart. J. Physiol. (Lond.) 251: 549-559. 
40. Prasad K, P. K. Singal, and J. C. Khatter. 1978. Frequencydependent changes in the electromechanical and $\left(\mathrm{Na}^{+}, \mathrm{K}^{+}\right)$ATPase activity of cardiac muscle. In Heart Function and Metabolism; T. Kobayashi, T. Sano, N. S. Dhalla, editors. University Park Press, Baltimore. 121-130.

41. Weidmann, S. 1956. Shortening of the cardiac action potential due to a brief injection of $\mathrm{KCl}$ following the onset of activity. J. Physiol. (Lond.) 132: 157-163.

42. Leaf, A. 1973. Cell swelling: a factor in ischemic tissue injury. Circulation. 48: 455-458.

43. Pine, M. B., D. Kahne, B. Jaski, C. S. Apstein, K. Thorp, and W. H. Abelmann. 1980. Sodium permeability and myocardial resistance to cell swelling during metabolic blockade. Am. J. Physiol. 239: H31-H39.

44. Poole-Wilson, P., P. D. Bourdillon, and D. P. Harding. 1979. Influence of contractile state on the size of the extracellular space in isolated ventricular myocardium. Basic Res. Cardiol. 73: 604-610.

45. Lee, C. O., and W. M. Armstrong. 1974. State and distribution of potassium and sodium ions in frog skeletal muscle. J. Membr. Biol. 15: 331-362.

46. Wiggins, P. M. 1979. Metabolic control of the properties of intracellular water as a universal driving force for active transport. In Cell-associated Water. W. Drost-Hansen and J. Clegg, editors. Academic Press, Inc. New York. 69-114.

47. Noble, D. 1975. The Initiation of the Heartbeat. Clarendon Press, Oxford. 103-117.

48. Katz, A. M. 1972. Increased $\mathrm{Ca}^{++}$entry during the plateau of the action potential: a possible mechanism of cardiac glygoside action. J. Mol. Cell. Cardiol. 4: 87-89.

49. Hondeghem, L. M., and R. Stroobandt. 1974. Purkinje fibers of sheep papillary muscle: occurrence of discontinuous fibers. Am. J. Anat. 141: 251-262.

50. Polimeni, P. I., and M. Vassalle. 1971. On the mechanism of ouabain toxicity in Purkinje and ventricular muscle fibers at rest and during activity. Am. J. Cardiol. 27: 622-629.

51. Hoffman, B. F., and P. F. Cranefield. 1960. Electrophysiology of the Heart. McGraw-Hill, Inc., New York.

52. Miura, D. S., B. F. Hoffman, and M. R. Rosen. 1977. The effect of extracellular potassium on the intracellular potassium ion activity and transmembrane potentials of beating canine cardiac Purkinje fibers. J. Gen. Physiol. 69: 463-479. 